\title{
A modified dot-blot method of protein determination applied in the tannin-protein precipitation assay to facilitate the evaluation of tannin activity in animal feeds
}

\author{
E. M. Hoffmann, S. Muetzel and K. Becker* \\ Institute for Animal Production in the Tropics and Subtropics (480), University of Hohenheim, Fruwirthstr. 12, \\ D-70593 Stuttgart, Germany
}

(Received 24 April 2001 - Revised 5 November 2001 - Accepted 13 January 2002)

\begin{abstract}
Tannins have received considerable attention from animal nutritionists as potential agents for modifying ruminal fermentation patterns, or for exploring new feed resources. This group of secondary plant compounds is defined by their ability to form complexes with proteins. A widely accepted method for assaying the biological activity of extracted tannins is the precipitation of bovine serum albumin. The protein carries a radioactive label $\left({ }^{125} \mathrm{I}\right)$ to allow direct quantification from the precipitate. Tannin-protein complexes dissolve in sodium dodecylsulfate solution. A dot-blot assay for protein determination, which is based on the reversible binding of a fluorochrome, benzoxanthene yellow, to the protein spots and is not disturbed by the presence of detergents, can replace the radioactive method by a fluorimetric measurement. A novel alternative to the last part of the dot-blot assay is to scan the stained protein spots in situ using a video camera and computer image analysis. Several filter sets were tested and, within a concentration range of $0.1-2.0 \mathrm{mg}$ protein $/ \mathrm{ml}$, each of them yielded results identical to the original method while the time required was only $30 \%$ of the working time consumed by the original procedure. The modified dot-blot assay should be applicable to the evaluation of tannin activity in all shrub and tree foliages considered as animal feed.
\end{abstract}

Protein determination: Benzoxanthene yellow: Tannin activity: Feed evaluation

The effects of tannins on ruminal digestion of protein is a topic of great current interest in animal nutrition. Tannins are defined as polyphenolic, secondary plant compounds that are able to precipitate protein. They are of diverse chemical structure, but can be distinguished in two groups; hydrolysable and condensed tannins. Hydrolysable tannins are oligo- and polymers of gallic and ellagic acid (Mueller-Harvey, 2001), while condensed tannins are derivatives of proanthocyanidins (Schofield et al. 2001). Condensed tannins in particular have multiple effects in the digestive tract of herbivores, as summarized by Barry \& McNabb (1999), but hydrolysable tannins also influence protein and fibre digestibility, especially in ruminal fermentation. Extraction of a given leaf material with methanol or acetone usually yields a mixture of both hydrolysable and condensed tannins. The composition of these tannin extracts may be complex, and even if various compounds are purified, chemical analysis cannot predict their biological activity (Hagerman et al. 1992). A widely used assay for the biological activity of tannin extracts is the tannin-protein precipitation method according to Hagerman et al. (1998). The extracts are mixed with a standard protein (bovine serum albumin; BSA) labelled with ${ }^{125} \mathrm{I}$, and complexes are allowed to form. Precipitates are harvested by centrifugation, and BSA is quantified by scintillation counting. While this method is very quick and reliable, it has the disadvantage of requiring the use of a radioactive isotope.

Proteins and tannins can be liberated from the complexes by resolubilization with sodium dodecylsulfate. This has been used to quantify the amount of tannins captured in the precipitated complexes (Makkar et al. 1988). The resolubilized samples, however, may also be used for protein determination in an assay insensitive to the presence of detergents, such as the dot-blot assay (Neuhoff et al. 1979; Guttenberger et al. 1991). This assay is based on the reversible binding of a fluorescent dye, benzoxanthene yellow, to samples immobilized on a nitrocellulose membrane, and tolerates many conditions that interfere with common protein determination methods (Lowry et al.

\footnotetext{
Abbreviations: BSA, bovine serum albumin; SDS, sodium dodecylsulfate.

* Corresponding author: Professor Dr K. Becker, fax +49 711459 3702, email kbecker@uni-hohenheim.de
} 
1951; Bradford, 1976). It is highly sensitive and needs only small amounts of sample $(3 \times 2 \mu l)$. It was originally developed for medical diagnosis, and, as a scientific tool, was mostly used with other micromethods (Guttenberger et al. 1994). However, it failed to gain wider acceptance because it involved time-consuming and laborious procedures such as cutting out individual sample spots for elution and fluorimetric quantification.

In the work presented below we show that this assay can replace the radioactive method of protein determination in the tannin-protein precipitation assay and we evaluate a modification of the dot-blot assay in which the dye bound to the spots is quantified by video documentation and image analysis of the entire membrane. If this approach is used instead of the fluorimetric measurement, the time required is reduced by approximately $70 \%$ of that needed for the original protocol.

\section{Material and methods}

\section{Extraction of tannins}

Leaves of two tropical plants, Acacia angustissima and Entada abissinica, were shade-dried at ambient temperature to minimize oxidative modification of phenolic compounds. They were ground to a fine powder and tannins were extracted in aqueous methanol $(500 \mathrm{ml} / \mathrm{l})$ as described in Makkar et al. (1988). Phenol and tannin content are given in Table 1. Total phenols and total tannins were determined by the ferric chloride assay using the entire extract, or after tannin-protein precipitation, respectively, as described by Makkar et al. (1988). Condensed tannins were determined by the butanol- $\mathrm{HCl}$ assay according to Porter et al. (1986).

\section{Tannin-protein precipitation}

Samples of $20,40,60$, and $80 \mu \mathrm{l}$ of tannin extract were made up to $100 \mu \mathrm{l}$ with aqueous methanol $(500 \mathrm{ml} / \mathrm{l})$, and added to $1 \mathrm{ml}$ of a solution of $2 \mathrm{mg} / \mathrm{ml}$ BSA (fraction V, Sigma $)$ in acetate buffer $(0.20 \mathrm{M}$ acetic acid, $0.17 \mathrm{M} \mathrm{NaCl}$, $\mathrm{pH}$ 4.9). Tannin-protein complexation was allowed to proceed overnight at $4^{\circ} \mathrm{C}$. After that, the samples were centrifuged $\left(10000 \mathrm{~g}, 10 \mathrm{~min}, 4^{\circ} \mathrm{C}\right)$ and the supernatant fraction was discarded. The pellets were washed once in an acetate buffer-aqueous methanol mixture $(2: 1, \mathrm{v} / \mathrm{v})$, and used for protein determination.

\section{Protein determination by scintillation counting}

The procedure of Hagerman et al. (1998) was applied. The
BSA solution used for tannin-protein precipitation was mixed with dialysed, radiolabelled $\left[{ }^{125} \mathrm{I}\right]$ BSA (ICN Biomedicals, Costa Mesa, CA, USA) to obtain a suitable activity (about $500 \mathrm{~Bq}$ in $50 \mu \mathrm{l}$ ). The samples were mixed with serial dilutions of tannin extracts as stated above. Precipitated protein was pelleted by centrifugation, washed, and then directly evaluated in a Gamma 4000 counter (Beckman, Fullerton, CA, USA).

\section{Protein determination by dot-blot assay}

Pellets generated from unlabelled BSA were resolubilized in SDS solution $(10 \mathrm{~g} / \mathrm{l})$. Triplicate $2 \mu \mathrm{l}$ samples from each solubilized pellet were applied to a nitrocellulose membrane (Sartorius 12200) and stained for $15 \mathrm{~min}$ with benzoxanthene yellow (Hoechst 2495 obtained from Sigma, $40 \mathrm{mg} / 100 \mathrm{ml}$ in destaining solution, i.e. a methanol-glacial acetic acid mixture $(9: 1, \mathrm{v} / \mathrm{v}))$ as described in Guttenberger et al. (1991). After destaining $(2 \times 5 \mathrm{~min}, 1 \times$ $15 \mathrm{~min}$ in destaining solution) and equilibration in drying solution ( $2 \mathrm{~min}$ in butanol-methanol-acetic acid (6:3:1, by $\mathrm{v} / \mathrm{v})$ ) the membranes were air-dried. The spots were cut out and placed in $2 \mathrm{ml}$ elution buffer $(0.25 \mathrm{M}$ glycine, $7.5 \mathrm{mM} \mathrm{H}_{2} \mathrm{SO}_{4}, 0.2 \mathrm{~g} / \mathrm{l} \mathrm{SDS}$ ) in a vial which was continuously shaken for $45 \mathrm{~min}$. The concentration of dye in the eluate was determined by fluorimetry at excitation and emission wavelengths of 425 and $475 \mathrm{~nm}$, respectively (Luminescence Spectrometer LS 50 B; Perkin-Elmer, Beaconsfield, UK). A serial dilution of BSA blotted onto each membrane was used for calibration.

\section{Video documentation and data processing}

The original procedure of the dot-blot assay was followed, but the last destaining step was extended overnight at $4^{\circ} \mathrm{C}$ to avoid background fluorescence. After equilibration of the membrane in drying solution the wet membrane was placed into the DIANA 1.6 video documentation system (Raytest GmbH, Straubenhardt, Germany). Fluorescence was excited either by u.v. illumination from below, or by epi-illumination at $425 \mathrm{~nm}$. The fluorescent intensity of the spots was recorded through a $475 \mathrm{~nm}$ filter, or through a commercially available (Raytest $\mathrm{GmbH}$, Straubenhardt, Germany) Sypro Green filter $(520 \mathrm{~nm})$. The membrane was scanned several times and the signal integrated until saturation of exposure was reached. The AIDA 2.31 software (Raytest GmbH, Straubenhardt, Germany) was used for image analysis.

Table 1. Content of total phenols, total tannins, and condensed tannins in Acacia angustissima and Entada abissinica

\begin{tabular}{lcc}
\hline & Acacia & Entada \\
\hline Total phenols* $^{*} \mu \mathrm{g}$ tannic acid equivalents $\left./ \mathrm{mg} \mathrm{DM}\right)$ & 38.1 & 16.6 \\
Total tannins ${ }^{*} \mu \mathrm{g}$ tannic acid equivalents $\left./ \mathrm{mg} \mathrm{DM}\right)$ & 37.3 & 15.3 \\
Condensed tanninst $(\mu \mathrm{g}$ leucocyanidin equivalents/mg DM) & 0.75 & 0.71 \\
\hline
\end{tabular}

*By ferric chloride assay.

† By butanol- $\mathrm{HCl}$ assay. 


\section{Statistics}

All experiments are based on triplicates unless stated otherwise. MS Excel 2000 (Microsoft, Redmont, WA, USA) was used for linear regression analysis. According to $y=\mathrm{a} x+\mathrm{b}, \mathrm{SE}_{\mathrm{a}}$ denotes the standard error of the regression coefficient, $\mathrm{SE}_{\mathrm{b}}$ the error of the intercept. Logarithmic regression analysis was done in GraphPad Prism version 2 (Graphpad Software, San Diego, CA, USA) using the model $y=\mathrm{A} \times \log (x+\mathrm{B})+\mathrm{C}$. $\mathrm{SE}_{\mathrm{A}}$ denotes the standard error of the regression coefficient in this system. A two-sided Student's $t$ test was used for the comparison of regression parameters. The probability values for difference were calculated in STATISTICA version 5.1 (Statsoft Inc., Tulsa, OK, USA); values below 0.05 were considered to be significant.

\section{Results}

Comparison of $\left[{ }^{125} I\right]$ bovine serum albumin assay and the original dot-blot method for quantification of tanninprecipitated bovine serum albumin

Tannin extracts of Acacia angustissima and Entada abissinica were subjected to the precipitation assay. Precipitated

${ }^{125}$ I-labelled BSA was quantified in a scintillation counter. Unlabelled BSA pellets were resolubilized in SDS-buffer and the protein concentration was determined by the original dot-blot method.

According to Hagerman et al. (1998) the slope within the linear range of the precipitation curves reflects the biological activity of the tannins. As shown in Fig. 1 there was no significant difference between the slopes derived from the radioactive assay and from the dot-blot assay. Both methods clearly show that tannin activity in Acacia is nearly two times higher than in Entada. However, the absolute amount of precipitated BSA was consistently lower by about $20 \mu \mathrm{g}$ when determined by fluorescence. In Fig. 2 fluorimetric data were plotted against those obtained by the radioactive method and regression analysis gave an intercept of -20 which corresponds quite well to the difference observed between the precipitation curves. According to the results obtained here the dot-blot assay is a suitable substitute for the radiolabelling assay. The major drawbacks to its application are the laborious procedure of cutting out and eluting the individual spots, and the necessity for a fluorimeter.

We therefore tested the alternative strategy of evaluating the intact membrane by image analysis.

\section{Comparison of fluorimetric evaluation and camera evaluation in the dot-blot assay}

For direct comparison of fluorimetry and video documentation, images of membranes were first recorded in the camera, and then the membranes were processed further according to the original protocol. Thus, each spot was quantified in both ways. Three independent tests of this kind were performed on different days. The calibration curves from these experiments are shown in Fig. 3, from which it is apparent that different calibration modes are required for the two methods. The fluorimetric data (original method) are calibrated by linear regression. Linearity is preserved over three orders of magnitude, and thus a high degree of extrapolation is possible in both directions (Neuhoff et al. 1979). The camera data, on the other hand, best fitted a logarithmic regression (data obtained by u.v.-Sypro Green filter combination). This implies a smaller usable concentration range and limits extrapolation. The lower detection limit of the camera method is around $0.05 \mathrm{mg} / \mathrm{ml}$ while the determination of high concentrations becomes increasingly inaccurate as the slope flattens out. The useful range is thus limited to $0 \cdot 1-1.0 \mathrm{mg} / \mathrm{ml}$.

In spite of the different calibration modes there was a very good correlation between the data obtained by fluorimetry and camera image analysis. If camera data are plotted against fluorimetric data (Fig. 4), regression yielded $y=1.050 x-0.005$. A slope of exactly 1.000 with no intercept would be expected in the case of a perfect match. In fact, with a standard error of 0.0096, the intercept was not significantly different from zero $(P=0 \cdot 601)$, but
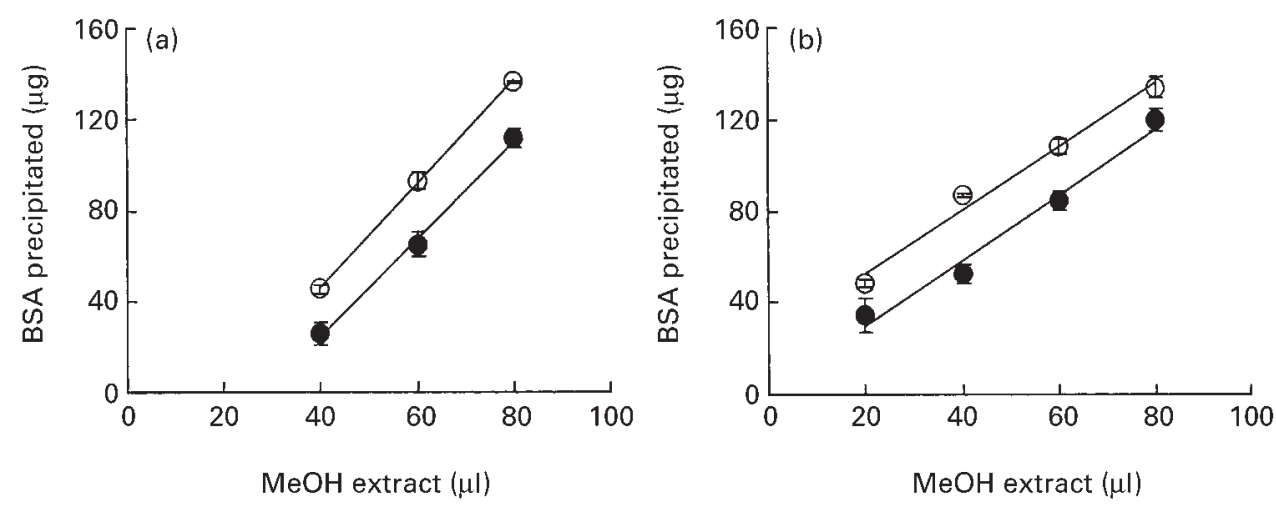

Fig. 1. Tannin-protein precipitation assay with extracts from (a) Acacia angustissima and (b) Entada abissinica. Tannin-precipitated bovine serum albumin (BSA) was determined by radioactivity $(O)$ or by dot-blot assay and fluorimetry $(\bullet)$. The slopes of the precipitation curves, that indicate tannin activity, are similar for both methods. This was statistically confirmed by regression analysis. For Acacia, ${ }^{125} \mathrm{I}$ assay: $y=$ $2.286 x-45.44 ; r^{2}=0.9992$; fluorimetry: $y=2.155 x-61.78 ; r^{2}=0.9974$; with standard errors for the regression coefficients (SEa) of 0.067 and 0.110 respectively, and $1 \mathrm{df}$, there is no significant difference between these slopes $(P=0.328)$. For Entada, ${ }^{125}$ I assay: $y=$ $1.393 x+24.75 ; r^{2}=0.9844$; fluorimetry: $y=1.435 x+0.92 ; r^{2}=0.9800$; again, with an $\mathrm{SE}_{\mathrm{a}}$ of 0.124 and 0.145 respectively, and df $=2$, there is no significant difference between the slopes $(P=0.705)$. $\mathrm{MeOH}$, methanol. 


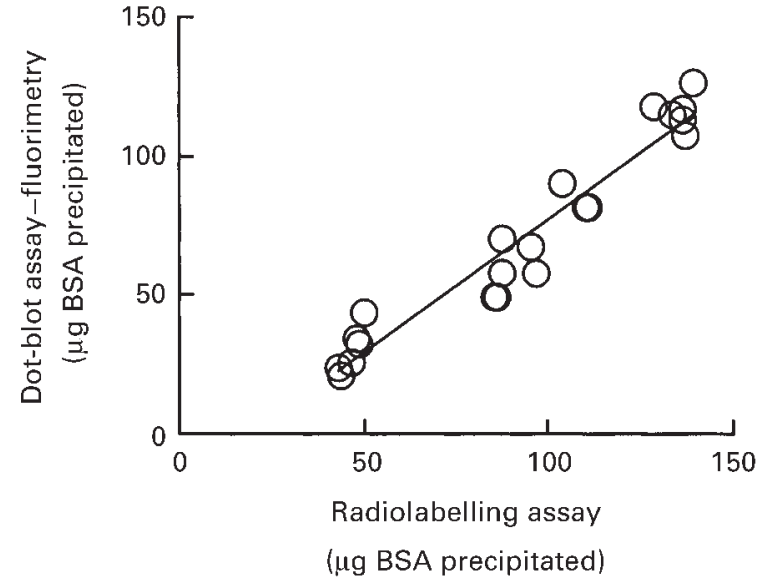

Fig. 2. Regression analysis of protein determination by the ${ }^{125}$ I radiolabelling assay and by the dot-blot assay and fluorimetry $(y=$ $\left.0.964 x-19.40 ; \mathrm{SE}_{\mathrm{a}}=0.058 ; \mathrm{SE}_{\mathrm{b}}=5.821 ; r^{2}=0.9343\right)$. With $\mathrm{df}=$ 19 the slope is not significantly different from $1(P=0.532)$; the intercept of about $-20 \mu \mathrm{g}$ corresponds to the shift in absolute values observed in the precipitation assay. BSA, bovine serum albumin.

the slope had a standard error of $0 \cdot 019$, and so in statistical terms was different from 1.000 albeit very slightly $(P=0 \cdot 011)$.

\section{Test of various filter combinations}

In the original fluorimetric assay benzoxanthene yellow is excited at $425 \mathrm{~nm}$, and emission is recorded at $475 \mathrm{~nm}$, i.e. the maxima of the benzoxanthene yellow spectrum. The same filter combination was therefore purchased for the DIANA camera. However, these unusual wavelengths, with a very narrow range, are not available in the standard filter programs of video documentation systems. The spectral properties of the dye should also allow excitation by u.v. light (maximum at $245 \mathrm{~nm}$ ), and fluorescence recording with a Sypro Green filter $(520 \mathrm{~nm})$. The filter combinations: u.v.-Sypro Green, $425 \mathrm{~nm}-475 \mathrm{~nm}$, u.v. $-475 \mathrm{~nm}$ were therefore tested for applicability in the modified dot-blot assay.

The calibration curves were equally good for all the filter combinations tested (Fig. 5). The highest signal intensity (i.e. the lowest number of scans needed to reach saturation of exposure) was achieved with the u.v. $-475 \mathrm{~nm}$ set. The u.v. $-475 \mathrm{~nm}$ combination was therefore chosen for routine application. In twelve independent assays the correlation coefficient of the calibration curve was $r^{2}=0.9940$ (SD 0.0043) (n 12).

To evaluate the performance of the filter sets in different concentration ranges, three serial dilutions of BSA were blotted on the same membrane, covering ranges of $0.1-$ $1.0 \mathrm{mg} / \mathrm{ml}, 0.2-2.0 \mathrm{mg} / \mathrm{ml}$, and $1.0-5.0 \mathrm{mg} / \mathrm{ml}$. Each membrane was recorded with all three filter combinations, and each of those datasets was evaluated threefold, using one of the dilution series for calibration, while the other spots were read as samples (data not shown).

Determination of samples within the calibration range works well with all filter combinations for protein concentrations up to $2 \mathrm{mg} / \mathrm{ml}$. When protein concentrations

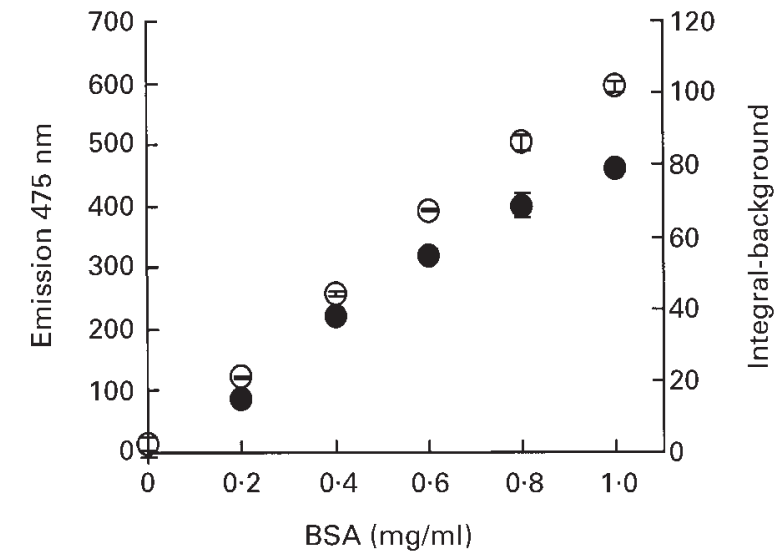

Fig. 3. Calibration modes for fluorimetry $(\bigcirc$, left axis) and video documentation ( $\bullet$, right axis) in the dot-blot assay. According to Neuhoff et al. (1979) the data obtained by fluorimetry are calibrated by linear regression $\left(y=596.3 x+15.95 ; \quad \mathrm{SE}_{\mathrm{a}}=18.642 ; \quad r^{2}=\right.$ 0.9961 ), whereas the image analysis data are fit by a logarithmic regression $\left(y=290.7 \log (x+1.05)-9.96 ; \mathrm{SE}_{\mathrm{A}}=63.6 ; r^{2}=0.993\right)$. BSA, bovine serum albumin.

exceed this range, the highest accuracy is maintained with the u.v.-Sypro Green filter set, but image analysis will drastically underestimate the actual values. If a lower concentration range $(0 \cdot 1-1 \mathrm{mg} / \mathrm{ml})$ is chosen for calibration, extrapolations, even those below the $2 \mathrm{mg} / \mathrm{ml}$ limit, tend to overestimate the actual protein concentrations. The u.v. $-475 \mathrm{~nm}$ combination produces deviations of $30 \%$, and the u.v.-Sypro Green combination $20 \%$ when samples with more than $1.5 \mathrm{mg} / \mathrm{ml}$ are evaluated against a calibration up to $1 \mathrm{mg} / \mathrm{ml}$. The best results in this case are obtained with the original filter set $(5 \%$ deviation). These observations emphasize the limited concentration range of the modified assay as compared with the original Neuhoff et al. (1979) assay. On the other

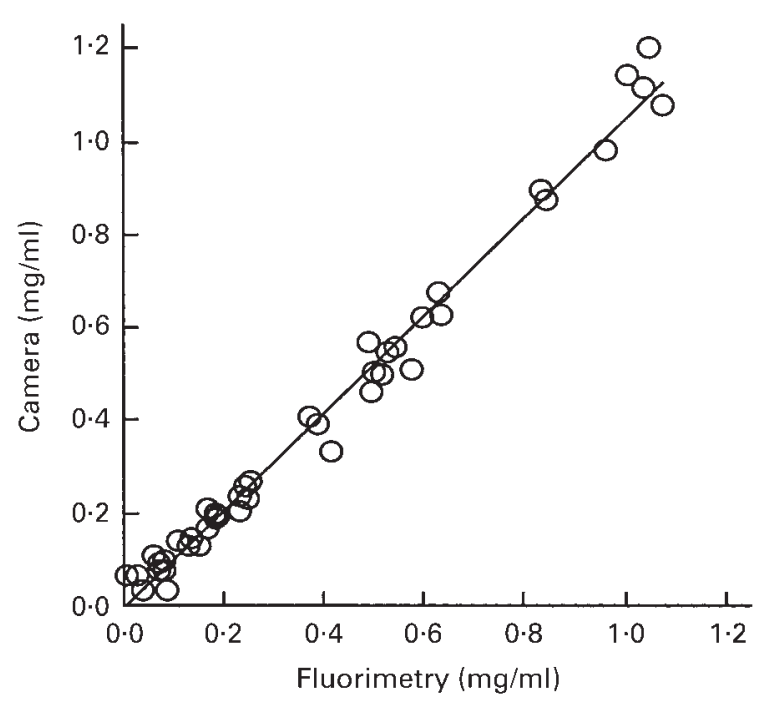

Fig. 4. Regression analysis of protein determination by fluorimetry and image analysis of the dot blot $\left(y=1.0504 x-0.0005 ; r^{2}=\right.$ $0.986)$. The intercept was not significantly different from zero $\left(\mathrm{SE}_{\mathrm{b}}=0.0096 ; \mathrm{df}=42 ; P=0.601\right)$. A small but statistically significant deviation from 1 was shown for the slope $\left(\mathrm{SE}_{\mathrm{a}}=0.019\right.$; $\mathrm{df}=$ 42; $P=0.011)$. 


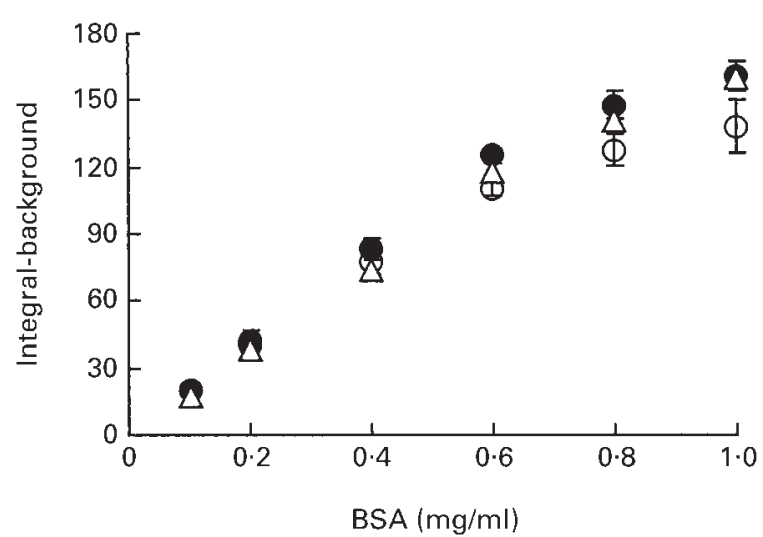

Fig. 5. Calibration of dot blots with different filter combinations: $425 \mathrm{~nm}-475 \mathrm{~nm}(\bigcirc)$, u.v. $-475 \mathrm{~nm}(\bullet)$, and u.v.-Sypro Green $(\Delta)$. The number of scans integrated to reach saturation of exposure was 5,2 , and 8 , respectively. This identified u.v. $-475 \mathrm{~nm}$ as the most sensitive combination. Calibration curves were calculated. For $425 \mathrm{~nm}-475 \mathrm{~nm}: y=211.63 \log (x+0.216)+123.81 ; \mathrm{SE}_{\mathrm{A}}=45.49$; $r^{2}=0.9791$. For u.v. $-475 \mathrm{~nm}: y=293.51 \log (x+0.314)+130.37$ $\mathrm{SE}_{\mathrm{A}}=67.44 ; \quad r^{2}=0.9821$. For u.v. - Sypro Green: $y=$ $412.62 \log (x+0.608)+77.70 ; \quad \mathrm{SE}_{\mathrm{A}}=96.39 ; \quad r^{2}=0.9903$. BSA, bovine serum albumin.

hand, within the calibration range the use of different filter combinations has virtually no effect, which points out a good adaptability of the modified method with respect to technical equipment.

\section{Repeated determination of the same samples}

In order to verify the reproducibility of the camera method for proteins other than the standard BSA, four arbitrary samples were blotted repeatedly in independent tests on four different days (Table 2). The protein concentration was determined according to a calibration on the same membrane. The low standard deviations illustrate the high accuracy of the modified dot-blot assay. For comparison, $5 \%$ variation was reported by Spector (1978) for the Coomassie Blue-based colorimetric protein determination. Note that leaf extracts and rumen fluid are intensely coloured samples that cannot be used without purification in colorimetric protein assays, such as the Bradford (1976) or the Lowry et al. (1951) assays.

\section{Discussion}

Many tropical shrubs and trees, that maintain their leaves throughout the dry season, contain high levels of phenols. This implies that their potential to be used as feed sup-

Table 2. Reproducibility of protein determination by the modified dot-blot assay in independent measurements on four different days

\begin{tabular}{lcc}
\hline Sample & $\begin{array}{c}\text { Protein content } \\
(\mathrm{mg} / \mathrm{ml})\end{array}$ & SD \\
\hline Casein & 0.48 & 0.038 \\
Leaf-protein extract & 0.59 & 0.049 \\
Leaf-protein extract and casein & 1.01 & 0.054 \\
Leaf-protein extract and rumen fluid & 0.87 & 0.054 \\
\hline
\end{tabular}

plements for ruminants is limited, unless the activity of the tannins can be evaluated reliably. Chemical quantification is not sufficient to predict the tannin activity of a given plant material. The protein precipitation assay has so far been accepted as a suitable method for estimating the biological activity of extracted tannins but it requires facilities for handling radioactive isotopes which may not be available in many developing countries of the tropics.

In the samples of Acacia and Entada analysed here, hydrolysable tannins are the major phenolic components, as only trace amounts of condensed tannins were detected. Tannin activity is not a simple quantitative parameter, but rather a qualitative description used for ranking the investigated materials in terms of feed quality. In the precipitation assays, less than $10 \%$ of the available BSA was actually complexed by the extracted tannins, but both methods gave precipitation curves which were linear over the same range of concentrations of the tannin extracts. There was a small systematic deviation in the estimation of the absolute quantity of precipitated BSA because the value given by the dot-blot method was always about $0.02 \mathrm{mg}$ lower than that determined by radioactivity. This was reflected in an intercept of -0.02 when fluorimetric data were plotted against radioactivity data. The reason for this deviation was not investigated further in the present study. If the slopes of the precipitation curves are taken as a measure for tannin activity, both methods yield the same results, indicating an almost twofold higher tannin activity in Acacia. This is in (exceptionally) good agreement with the higher phenol and tannin content of this material as determined by chemical analysis. The dot-blot assay may thus be used with confidence to replace the radioactive determination of tannin-precipitated BSA.

BSA standards were used to compare the data generated by camera evaluation with those obtained by fluorimetry. An excellent correlation was observed between the two modes of fluorescence detection. The regression line passed through the zero origin, and the slope was almost exactly $1 \cdot 0$. The difference of $0 \cdot 05$, although statistically significant, is hardly of practical relevance, since even at the maximium allowable concentration the introduced error would just reach the magnitude of the lower detection limit. The major disadvantage of the camera evaluation is the narrow range of protein concentration over which it can be used. On the other hand, the useful range covers the protein concentrations most likely to be encountered in the applications envisaged here. Acacia and Entada which were evaluated above by the more sensitive, original fluorimetric method would come close to the detection limit of the camera. But these samples had a very low phenol content, and therefore most of the tropical trees and shrubs can be expected to fall within the limits of the modified method.

To make the modified dot-blot assay applicable in laboratories with standard video equipment, three different filter combinations were tested in the image analysis. The separation of excitation and emission spectra is more critical in the camera evaluation than in fluorimetry, so that the u.v. $-475 \mathrm{~nm}$ filter combination was found to be superior to the original $425 \mathrm{~nm}-475 \mathrm{~nm}$ set. But even the combination of two standard filters (u.v.-Sypro Green) gave reasonable 
results. In general, video documentation does not allow any flexibility with respect to the protein concentration range. It yields excellent results in the working range between $0 \cdot 1-$ $1.0 \mathrm{mg}$ protein $/ \mathrm{ml}$, with all of the tested filter sets. Due care has to be taken that samples lie within the calibration range of the respective membrane. If these limitations are respected, results are identical to the fluorimetry method, but the working time is reduced by approximately $70 \%$.

\section{Conclusion}

Although the original dot-blot assay is a long and laborious process, it has a unique combination of advantageous features. It is insensitive to many interfering compounds, highly sensitive and linear over a wide concentration range (three orders of magnitude), and needs only a small amount of sample. However, most of these features, though impressive, are not critical in the tannin precipitation assay. The protein concentrations encountered here greatly exceed the lower detection limit, and stay within the same order of magnitude. The usual sample volume is at least 100 times higher than that actually needed. The main reason why the dot-blot assay was chosen to quantify BSA resolubilized after precipitation by tannins was because of its insensitivity to SDS. In this respect it proved an excellent replacement for the radioactive method of using ${ }^{125}$ I-labelled BSA. To make this test more feasible in routine applications we have developed a protocol that allows the quantification of fluorescent intensity (and thus protein concentration) by video documentation and image analysis. This involves some limitations with respect to sensitivity and concentration range (neither of which are critical in this application), but dramatically cuts down the time required. With this modification the dot blot assay is an attractive alternative to the radioactive method of protein determination when screening the biological activity of tannins and it should be applicable to the evaluation of tannin activity in all shrub and tree foliages encountered in tropical countries.

\section{Acknowledgements}

This work was funded by DFG grant no. Be 1133/7. We thank Dr A.E. Hagerman for the introduction in the radiolabelling assay, Professor Dr H. Rau for providing the fluorimeter, Dr M. Guttenberger for helpful discussions, Dr P. Lawrence for critical reading of the manuscript,
H. Richter for advice in statistics, and K. Beck for excellent technical assistence.

\section{References}

Barry TN \& McNabb WC (1999) The implications of condensed tannins on the nutritive value of temperate forages fed to ruminants. British Journal of Nutrition 81, 263-272.

Bradford MM (1976) A rapid and sensitive method for the quantitation of microgram quantities of protein utilizing the principle of protein-dye binding. Analytical Biochemistry $\mathbf{7 2}$, $248-254$.

Guttenberger M, Neuhoff V \& Hampp R (1991) A dot-blot assay for quantitation of nanogram amounts of protein in the presence of carrier ampholytes and other possibly interfering substances. Analytical Biochemistry 196, 99-103.

Guttenberger M, Schaeffer C \& Hampp R (1994) Kinetic and electrophoretic characterization of NADP dependent dehydrogenases from root tissues of Norway spruce (Picea abies (L.) Karst) employing a rapid one-step extraction procedure. Trees 8, 191-197.

Hagerman AE, Rice ME \& Ritchard NT (1998) Mechanisms of protein precipitation for two tannins, pentagalloyl glucose and epicatechin(16) $(4 \rightarrow 8)$ catechin (procyanidin). Journal of Agricultural and Food Chemistry 46, 2590-2595.

Hagerman AE, Robbins CT, Weerasuriya Y, Wilson TC \& Mcarthur C (1992) Tannin chemistry in relation to digestion. Journal of Range Management 45, 57-62.

Lowry OH, Rosebrough NJ, Farr AL \& Randall RJ (1951) Protein measurement with the Folin phenol reagent. Journal of Biological Chemistry 193, 265-275.

Makkar HPS, Dawra RK \& Singh B (1988) Changes in tannin content, polymerisation and protein precipitation capacity in oak (Quercus incana) leaves with maturity. Journal of the Science of Food and Agriculture 44, 301-307.

Mueller-Harvey I (2001) Analysis of hydrolysable tannins. Animal Feed Science and Technology 91, 3-20.

Neuhoff V, Philipp K, Zimmer HG \& Mesecke S (1979) A simple, versatile, sensitive and volume-independent method for quantitative protein determination which is independent of other external influences. Zeitung für Physiologische Chemie 360, 1657-1670.

Porter LJ, Hrstich LN \& Chan BG (1986) The conversion of procyanidins and prodelphinidins to cyanidin and delphinidin. Phytochemistry 25, 223-230.

Schofield P, Mbugua DM \& Pell AN (2001) Analysis of condensed tannins: a review. Animal Feed Science and Technology 91, $21-40$.

Spector T (1978) Refinement of the coomassie blue method of protein quantitation. Analytical Biochemistry 86, 142-146. 